\title{
Keçiborlu kükürt fabrikası flotasyon atıklarının ıslah edilmesi ve kamışsı yumak (Festuca arundinacea) çimiyle yeniden bitkilendirilmesi
}

\section{Reclamation of flotation wastes of Keçiborlu sulphur factory and phytoremediation with Festuca arundinacea grass}

\author{
Hüseyin KALKAN ${ }^{1}$, Mustafa KAPLAN ${ }^{2}$, Şule ORMAN $^{2}$ (Đ) \\ ${ }^{1}$ Akdeniz Üniversitesi, Kumluca Meslek Yüksekokulu, Bitkisel ve Hayvansal Üretim Bölümü, Bahçe Tarımı Programı, 07350, Antalya \\ ${ }^{2}$ Akdeniz Üniversitesi, Ziraat Fakültesi, Toprak Bilimi ve Bitki Besleme Bölümü, 07070, Antalya \\ Sorumlu yazar (Corresponding author): H. Kalkan, e-posta (e-mail): hkalkan@akdeniz.edu.tr \\ Yazar(lar) e-posta (Author e-mail): mkaplan@akdeniz.edu.tr, suleorman@akdeniz.edu.tr
}

\section{MAKALE BİLGİSİ}

Alınış tarihi 12 Mart 2019

Düzeltilme tarihi 19 Nisan 2019

Kabul tarihi 26 Nisan 2019

\section{Anahtar Kelimeler:}

Ağır metal

Ahır gübresi

Fitoremediasyon

Flotasyon atığı

Islah

\begin{abstract}
ÖZ
$\mathrm{Bu}$ çalışmada Isparta ili Keçiborlu kükürt fabrikası çevresinde bulunan flotasyon atık alanlarının iyileştirici materyaller kullanarak yeniden bitkilendirilmesi amacıyla flotasyon atığına (FA) 1slah amaçlı kireçli toprak (KT \%10-20-30-40) ve ahır gübresi (AG \%4-8) uygulandıktan sonra kamışsı yumak (Festuca arundinacea) çim çeşidi yetiştirilmiştir. Tesadüf blokları deneme desenine göre 10 farklı uygulama konusu ve 4 tekerrür üzerinden yürütülen çalışmada 6 kg’lık saksılar kullanılmıştır. Çalışma 12 hafta süreyle yürütülmüş ve bütün uygulamalar eşit şekilde sulanmıştır. Yetiştiricilik dönemi sonunda alınan ortam örneklerinde elektriksel iletkenlik (EC), pH, DTPA'da ekstrakte edilebilir demir (Fe), çinko (Zn), mangan $(\mathrm{Mn})$, bakır $(\mathrm{Cu})$, nikel $(\mathrm{Ni})$, krom $(\mathrm{Cr})$, kurşun $(\mathrm{Pb})$, kadmiyum $(\mathrm{Cd})$ ve kobalt (Co) elementlerinin analizleri yapılırken, bitki örneklerinde ise kuru madde verimi, $\mathrm{Fe}, \mathrm{Zn}, \mathrm{Mn}, \mathrm{Cu}$, $\mathrm{Ni}, \mathrm{Cr}, \mathrm{Pb}, \mathrm{Cd}$ ve $\mathrm{Co}$ elementlerinin analizleri yapılmıştır. Araştırma sonuçlarına göre flotasyon atığına artan oranlarda kireçli toprak ve ahır gübresi uygulamaları yetiştirilen çim bitkisinin kuru madde verimini artırıcı yönde etkilemiş ve özellikle ahır gübresinin \%8 oranında ilave edildiği uygulamalarda en yüksek değerlere ulaşılmıştır. Bitkide en yüksek Fe ve $\mathrm{Cu}$ içeriği \%72 FA + \%20 KT + \%8 AG; Zn, Mn ve Pb içeriği \%82 FA + \%10 KT + \%8 AG uygulamalarından elde edilmiştir. Yetiştirme ortamlarından ise en yüksek $\mathrm{Zn}, \mathrm{Cu}, \mathrm{Pb}$ ve Cd içeriği \%62 FA + \%30 KT + \%8 AG; EC, Fe ve Mn içeriği \%72 FA + \%20 KT + \%8 AG uygulamalarından elde edilmiştir. Flotasyon atığı + Kireçli toprak + Ahır gübresi uygulamalarında yetiştirme ortamlarının ağır metal içerikleri ahır gübresi ilave edilmeyenlere göre daha yüksek bulunmuştur.
\end{abstract}

\section{ARTICLE INFO}

Received 12 March 2019

Received in revised form 19 April 2019 Accepted 26 April 2019

\section{Keywords:}

Heavy metal

Farmyard manure

Phytoremediation

Flotation waste

Reclamation

\begin{abstract}
In this study, calcareous soil (10-20-30-40\%) and farmyard manure (4-8\%) as amendment materials were applied to flotation waste for revegetation of abandoned tailings pools in around Keçiborlu sulphur factory. As the experimental plant Festuca arundinacea was grown. In this purpose; pot (6 $\mathrm{kg}$ ) experiment carried out according to the completely randomized design factorial with 4 replicates and 10 different applications. All treatments were equally watered during 12 weeks. After experimental set up for 12 weeks, the samples of media and plant were taken for analysis. $\mathrm{pH}$, electrical conductivity (EC), DTPA-extractable iron (Fe), zinc ( $\mathrm{Zn})$, manganese $(\mathrm{Mn})$, copper $(\mathrm{Cu})$, nickel $(\mathrm{Ni})$, chromium $(\mathrm{Cr})$, lead $(\mathrm{Pb})$, cadmium $(\mathrm{Cd})$ and cobalt $(\mathrm{Co})$ concentrations of growing media, also, total $\mathrm{Fe}, \mathrm{Zn}, \mathrm{Mn}, \mathrm{Cu}, \mathrm{Ni}, \mathrm{Cr}, \mathrm{Pb}, \mathrm{Cd}, \mathrm{Co}$ concentrations of plants were analyzed together with the dry weight yield of the plant which were determined at end of the experiment. Increasing ratios of calcareous soil and farmyard manure into flotation waste were raised the dry material weight in grass plants and the highest result of the media were reached at the application of the highest farmyard manure $(8 \%)$. According to plant analysis results; the highest concentration of Fe and $\mathrm{Cu}$ were obtained from $72 \% \mathrm{FW}+20 \% \mathrm{CS}+8 \%$ FYM application; while $\mathrm{Zn}, \mathrm{Mn}$ and $\mathrm{Pb}$ concentration were obtained from $82 \% \mathrm{FW}+10 \% \mathrm{CS}+8 \% \mathrm{FYM}$ application. According to the media analysis results; the highest concentration of $\mathrm{Zn}, \mathrm{Cu}, \mathrm{Pb}$ and $\mathrm{Cd}$ were determined in $62 \% \mathrm{FW}$ $+30 \% \mathrm{CS}+8 \%$ FYM application; while Fe and Mn concentration were determined in $72 \% \mathrm{FW}+$ $20 \%$ CS $+8 \%$ FYM application. However this work indicates that heavy metal concentrations increased CS with FYM more than CS-alone in media.
\end{abstract}




\section{Giriş}

Hava, su, toprak, bitki örtüsü, hayvanlar ve yaşadığımız gezegen üzerinde ve dışında olan, insanları etkileyen her türlü nesne çevre olarak adlandırılmaktadır. Çevre ve doğal kaynakların kirlenmeye karşı korunması, çevre kirliliğinin önlenmesi açısından son derece önemli olmakla birlikte, kirlenmiş alanların temizlenmesi de mevcut çevre kirliliklerinin çözümünde büyük önem arz etmektedir. Toprak kirliliŭi açısından bakıldığında, ağır metallerin en önemli kirletici kaynaklar arasında olduğu görülmektedir. Amerika Birleşik Devletleri Çevre Koruma Ajansı'nın (EPA) hazırladığı 129 tane öncelikli çevre kirleticiler arasında yer alan ağır metaller, en önemli çevre kirletici gruplardan birini oluşturmaktadır (Kocaer ve Başkaya 2003). Topraklara karışan ve buralarda birikme yapan ağır metaller, mikrobiyal aktiviteye, toprak verimliliğine, biyolojik çeşitlilik ve ürünlerdeki verim kayıplarına, hatta besin zinciri yoluyla sicakkanlılarda zehirlenmelere kadar birçok çevre ve insan sağlı̆̆ problemlerinin ortaya çıkmasına neden olabilmektedir. Ağır metaller zehir etkisi göstermesi nedeniyle çevredeki en tehlikeli maddelerden biri olarak kabul edilmektedir (Vanlı ve Yazgan 2006).

Hava, su ve toprak kalitesinin arttırılmasinda alternatif bir yöntem olarak kabul edilen fitoremediasyon; kirleticilerin bitkiler kullanılarak giderilmesi teknolojisine genel olarak verilen bir isimdir. (Cunningham ve ark. 1995; EPA 2000). Bitkilerce bir kirleticinin topraktan alınabilmesi için, öncelikle toprak şartlarının bitkinin isteklerine uygun olması gerekmektedir. Toprak pH'sı bu konuda en önemli parametrelerden biri olarak öne çıkmaktadır. Bununla birlikte toprağın toplam ağır metal içeriğine bağlı olmasının yanı sıra ağır metallerin bitkiye yarayışlılı̆̆ 1 ve değişik toprak bileşenleri ile oluşturduğu farklı çözünebilir kimyasal formlara bağlıdır (Sposito ve ark. 1982). Fitoremediasyon tekniğinde, topraktaki metalleri köklerine ve hasat edilebilen kısımlara nakledebilen hiperakümülatör bitkiler kullanılmaktadır. Topraktaki metal konsantrasyonundan bağımsız olarak, yapraklarında kuru ağırlık bazında \%0.1'den fazla $\mathrm{Ni}, \mathrm{Co}, \mathrm{Cu}, \mathrm{Cr}$ veya $\% 1 \mathrm{Zn}$ ve $\mathrm{Mn}$ içeren bitkiler hiperakümülatör olarak isimlendirilmektedir (Raskin ve ark. 1994). Bu bitkilerin topraktan ağır metal alımına karş1 yüksek oranda etkili olduğu ve ağır metal zehirliliğine karşı toleranslı olduğu belirlenmiştir (Cunningham ve ark. 1996).

Birçok asit oluşturan maden atıklarının asit koşullarının bertarafi için 1slah materyali olarak yaygın bir biçimde kireç kullanılmaktadır. Asitliğin düzeltilmesi sadece bitkilerin geniş bir alanda yayılmasını olanaklı kılmaz, aynı zamanda metal toksisitesini hafifletir ve bitki besin elementlerinin yarayışlılığını arttırır (Johnson ve ark. 1994). Çiftlik gübresi yaygın bir şekilde atık ıslah edici olarak kullanılmaktadır. Çünkü organik madde ilavesi maden atıklarının besin elementi durumlarını ve fiziksel özelliklerini önemli bir şekilde iyileştirebilir. İlave olarak kimyasal gübreler, maden atıklarının başarılı bir şekilde ıslah edilmesinde temel parçadır (Bradshaw ve Chadwick 1980).

Ülkemizin önemli kükürt maden ocaklarından biri olan Isparta Keçiborlu kükürt maden ocakları yaklaşık 55-60 y1 işletildikten sonra rezervlerin tükenmesiyle terk edilmiştir (Gülcü ve ark. 2007). Bu çalışma Keçiborlu kükürt fabrikası flotasyon atıklarının sslah edilmesi ve kamışsı yumak (Festuca arundinacea) çimiyle yeniden bitkilendirilmesine yönelik olarak flotasyon atığına değişik oranlarda uygulanan kireçli toprak ve ahır gübresinin etkilerinin belirlenmesi amacıyla yürütülmüştür.

\section{Materyal ve Yöntem}

Çalışmada; flotasyon atığı, kireçli toprak, ahır gübresi ve kamışsı yumak (Festuca arundinacea) çim bitkisi deneme materyalleri olarak kullanılmıştır. Çizelge 1'de denemede kullanılan materyallere ilişskin analiz sonuçları verilmiştir. Denemede kullanılan flotasyon atığı, Isparta'da Keçiborlu Kükürt Fabrikası atık havuzu alanlarından temin edilmiştir. Deneme için kullanılan kireçli toprak ise Akdeniz Üniversitesi kampus alanından sağlanmış olup, Gölbaşı serisine aittir. Ayrıca organik materyal olarak kullanılan ahır gübresi, Antalya'nın Serik ilçesinde yaşayan ve hayvancılık ile uğraşan bir çiftçiden sağlanmıştır. Bitki materyali olarak Avrupa ve Akdeniz çevresindeki çim türlerine göre uzun boylu, kaba yapılı, kalın ve sert yapraklı, yumak şeklinde gelişim gösteren kamışsı yumak (Festuca arundinacea) çim türü kullanılmıştır (Açıkgöz 1994). Araştırma Antalya havzasının sahil kesimindeki tipik Akdeniz iklim kuşağında yer alan Akdeniz Üniversitesi Kampus alanı içerisinde deneme için belirlenen saksı sayısını bünyesinde barındırabilecek, üzeri \%95'lik gölge tülü ile kapatılmış yüksek tünelde yürütülmüştür (Sarı ve ark. 1993).

Çizelge 1. Araştırmada kullanılan materyallere ait bazı fiziksel ve kimyasal analiz sonuçları.

Table 1. Some physical and chemical properties of materials used in study.

\begin{tabular}{|c|c|c|c|}
\hline Parametre & $\begin{array}{l}\text { Flotasyon } \\
\text { Atığı (FA) }\end{array}$ & $\begin{array}{c}\text { Ahır Gübresi } \\
\text { (AG) }\end{array}$ & $\begin{array}{c}\text { Kireçli } \\
\text { Toprak (KT) }\end{array}$ \\
\hline $\mathrm{pH}$ & 3.12 & 7.62 & 7.97 \\
\hline $\mathrm{EC} \mathrm{dS} \mathrm{m} \mathrm{m}^{-1}$ & 9.99 & 4.73 & 0.16 \\
\hline $\mathrm{CaCO}_{3} \%$ & 1.61 & 9.66 & 48.25 \\
\hline $\mathrm{N} \%$ & 0.038 & 2.13 & 0.035 \\
\hline $\mathrm{P}_{\mathrm{mg} \mathrm{kg}}^{-1}$ & 0.17 & 3876.16 & 0.49 \\
\hline $\mathrm{K} \mathrm{mg} \mathrm{kg}^{-1}$ & 0.00 & 6767.84 & 23.87 \\
\hline $\mathrm{Ca} \mathrm{mg} \mathrm{kg}^{-1}$ & 1442.00 & 36362.10 & 1442.00 \\
\hline $\mathrm{Mg} \mathrm{mg} \mathrm{kg}{ }^{-1}$ & 406.00 & 5116.83 & 130.00 \\
\hline Na mg.kg ${ }^{-1}$ & 4.92 & 0.15 & 15.01 \\
\hline Fe mg.kg ${ }^{-1}$ & 6250.00 & 3582.50 & 3.53 \\
\hline Zn mg.kg-1 & 8.17 & 152.58 & 1.18 \\
\hline Mn mg kg & 53.21 & 75.58 & 3.00 \\
\hline $\mathrm{Cu} \mathrm{mg} \mathrm{kg}^{-1}$ & 10.30 & 2.56 & 0.59 \\
\hline Co mg kg ${ }^{-1}$ & 5.82 & 0.27 & 0.04 \\
\hline $\mathrm{Ni} \mathrm{mg} \mathrm{kg}^{-1}$ & 64.84 & 28.09 & 0.11 \\
\hline $\mathrm{Cr} \mathrm{mg} \mathrm{kg}{ }^{-1}$ & 14.86 & 57.56 & 0.02 \\
\hline $\mathrm{Pb}$ mg.kg ${ }^{-1}$ & 0.53 & 5.35 & 0.16 \\
\hline $\mathrm{Cd} \mathrm{mg} \mathrm{kg}{ }^{-1}$ & 0.13 & 0.56 & 0.01 \\
\hline
\end{tabular}

Saksı denemesinde yetiştirme ortamı olarak kullanmak amacıyla Isparta/ Keçiborlu Kükürt Fabrikası atık havuzu alanlarından temin edilen flotasyon atığı ve Akdeniz üniversitesi kampus alanı Gölbaşı serisine ait kireçli toprak örnekleri alındıktan sonra toprak hava kurusu hale getirilip ardından $4 \mathrm{~mm}$ 'lik elekten elenmiştir. Kullanılan materyaller toplam ağırlığı her bir saksıda $6.0 \mathrm{~kg}$ olacak şekilde, belirlenen oranlarda homojen bir karışım elde edilerek ahır gübreli ve ahır gübresiz olarak $510 \times 165 \times 125 \mathrm{~mm}$ ebatlarındaki saksılara doldurulmuştur. Ayrıca denemeye başlamadan başlangıç aşamasında her saksıya $150 \mathrm{~kg} \mathrm{da}^{-1}$ olacak şekilde 15.15 .15 kimyasal gübresinden uygulanmıştır. $1 \mathrm{~m}^{2}$ alana $100 \mathrm{~g}$ tohum esasına göre her saksının $0-2 \mathrm{~cm}$ derinliğine ekim işlemi yapıldıktan sonra çimlenmenin etkili bir şekilde olması amacıyla tohumların üzeri torf ile ince bir tabaka halinde örtülerek ekim işlemi tamamlanmıştır. Belirlenen 10 uygulama 
(Çizelge 2) 4 tekerrürlü olarak tesadüf blokları deneme desenine göre (10 Uygulama x 1 Bitki Çeşidi x 4 tekerrür= 40) yapılmıştır. Deneme süresi 12 hafta olarak planlanmış ve Haziran 2007 tarihinde başlayıp, Eylül 2007 tarihinde sonlandırılmıştır. Bütün uygulamaların sulamaları eşit şekilde yapılmıştır. Deneme süresince her saksıda bulunan çim bitkileri 5 kez biçilmiş ve tüm biçimlerden elde edilen örnekler tek bir örnek haline getirilmiştir. Deneme sonunda, bitkilerin yetiştiği her saksıdan ortam örnekleri alınmıştır. Alınan ortam örneklerinde $\mathrm{EC}, \mathrm{pH}, \mathrm{Fe}, \mathrm{Zn}, \mathrm{Mn}, \mathrm{Cu}, \mathrm{Ni}, \mathrm{Cr}, \mathrm{Pb}, \mathrm{Cd}$ ve $\mathrm{Co}$ elementlerinin analizleri yapılırken, bitki örneklerinde ise kuru madde verimi, $\mathrm{Fe}, \mathrm{Zn}, \mathrm{Mn}, \mathrm{Cu}, \mathrm{Ni}, \mathrm{Cr}, \mathrm{Pb}, \mathrm{Cd}$ ve $\mathrm{Co}$ elementlerinin analizleri yapılarak meydana gelen değişim incelenmiştir.

Çizelge 2. Deneme saksılarında yetiştirme ortamlarını hazırlamak için kullanılan materyallerin karışım oranları.

Table 2. Composition of materials used for preparing cultivation media in pot trial.

\begin{tabular}{|c|c|}
\hline Uygulamalar & Karışım Oranları \\
\hline FA. $\mathrm{KT}_{10}$ & $\% 90 \mathrm{FA}+\% 10 \mathrm{KT}$ \\
\hline FA. $\mathrm{KT}_{20}$ & $\% 80 \mathrm{FA}+\% 20 \mathrm{KT}$ \\
\hline FA. $\mathrm{KT}_{30}$ & $\% 70 \mathrm{FA}+\% 30 \mathrm{KT}$ \\
\hline FA. $\mathrm{KT}_{40}$ & $\% 60 \mathrm{FA}+\% 40 \mathrm{KT}$ \\
\hline FA. $\mathrm{KT}_{10} \mathrm{AG}_{4}$ & $\% 86 \mathrm{FA}+\% 10 \mathrm{KT}+\% 4 \mathrm{AG}$ \\
\hline FA. $\mathrm{KT}_{10} \mathrm{AG}_{8}$ & $\% 82 \mathrm{FA}+\% 10 \mathrm{KT}+\% 8 \mathrm{AG}$ \\
\hline FA. $\mathrm{KT}_{20} \mathrm{AG}_{4}$ & $\% 76 \mathrm{FA}+\% 20 \mathrm{KT}+\% 4 \mathrm{AG}$ \\
\hline FA. $\mathrm{KT}_{20} \mathrm{AG}_{8}$ & $\% 72 \mathrm{FA}+\% 20 \mathrm{KT}+\% 8 \mathrm{AG}$ \\
\hline FA. $\mathrm{KT}_{30} \mathrm{AG}_{4}$ & $\% 66 \mathrm{FA}+\% 30 \mathrm{KT}+\% 4 \mathrm{AG}$ \\
\hline FA. $\mathrm{KT}_{30} \mathrm{AG}_{8}$ & $\% 62 \mathrm{FA}+\% 30 \mathrm{KT}+\% 8 \mathrm{AG}$ \\
\hline
\end{tabular}

Ortam örneklerinin pH (Jackson 1967), elektriksel iletkenlik (Anonim 1988), ağır metal alınabilir $\mathrm{Fe}, \mathrm{Zn}, \mathrm{Mn}, \mathrm{Cu}, \mathrm{Co}, \mathrm{Ni}$, $\mathrm{Cr}, \mathrm{Cd}$ ve $\mathrm{Pb}$ (Lindsay ve Norwell 1978) ICP-OES cihazı kullanılarak belirlenmiş ve sonuçlar $\mathrm{mg} \mathrm{kg}^{-1}$ olarak verilmiştir. Yetiştirme periyodu süresince saksı denemesinde her saksıdan 5 kez biçim sonucunda elde edilen toplam çim bitkilerinin ağırlığının $65^{\circ} \mathrm{C}$ 'de sabit ağırlığa ulaşıncaya kadar kurutulması sonucu kuru madde verimleri belirlenmiştir. Çim bitkilerinin Fe, $\mathrm{Zn}, \mathrm{Mn}, \mathrm{Cu}, \mathrm{Co}, \mathrm{Ni}, \mathrm{Cr}, \mathrm{Cd}$ ve $\mathrm{Pb}$, Kacar ve İnal (2008)'1n bildirdiği şekilde nitrik-perklorik asit karışımı ile yaş yakma sonucu elde edilen süzükte ICP-OES cihazı kullanılarak belirlenmiş ve değerler $\mathrm{mg} \mathrm{kg}^{-1}$ olarak verilmiştir.
Deneme uygulama konularının etkilerini belirlemek için, her bir konuya ait değerler bilgisayar ortamında MSTAT-C istatistik analiz programı (Freed ve ark. 1989) kullanılarak değerlendirilmiştir. Veriler bilgisayara girildikten sonra varyans analizi ve Duncan testine tabi tutulmuştur.

\section{Bulgular ve Tartışma}

Keçiborlu kükürt fabrikası flotasyon atığına değişen düzeylerde kireçli toprak ve ahır gübresi uygulamalarının deneme bitkisi olan kamışsı yumak (Festuca arundinacea)'ın yetiştirildiği ortamların pH, EC, ve ağır metal (Fe, $\mathrm{Zn}, \mathrm{Mn}, \mathrm{Cu}, \mathrm{Co}, \mathrm{Ni}, \mathrm{Cr}$, $\mathrm{Pb}, \mathrm{Cd})$ içerikleri üzerine olan etkileri Çizelge 3 'te ve Şekil 1 'de, deneme bitkisi olan kamışsi yumak (Festuca arundinacea)'ın kuru madde verimi ve ağır metal (Fe, $\mathrm{Zn}, \mathrm{Mn}$, $\mathrm{Cu}, \mathrm{Co}, \mathrm{Ni}, \mathrm{Cr}, \mathrm{Pb}, \mathrm{Cd}$ ) içerikleri üzerine olan etkileri Çizelge 4 'te ve Şekil 2'de verilmiştir. Analizleri yapılan parametreler üzerine olan etkileri istatistiksel olarak \%0.1 düzeyinde etkili bulunmuştur. Yetiştirme ortamlarının $\mathrm{pH}$ değerlerine bakıldığında sadece kireçli toprak ilavesi olan uygulamalarda değerin yükseldiği ve ahır gübresi uygulaması ile düşüşe geçtiği görülmektedir. EC değerleri için ise flotasyon atığının $9.99 \mathrm{dS}$ $\mathrm{m}^{-1}$ olan değerin tüm uygulamalarda düştüğünü ama ahır gübresi uygulamalarının bu değeri, sadece kireçli toprak uygulamalarına kıyasla az da olsa yükselttiğini söylemek mümkündür. Kirlenmiş alanlar uygun nem düzeyine ulaştıklarında hava ile oksidasyon ve sülfitlerin hidrolize uğraması sonucunda sülfürik asit oluşmaktadır. Bu asit ortam pH'sını düşürürken ağır metal çözünürlüğünü artırmaktadır (Williamson ve Johnson 1981; Simón ve ark. 1999). Kükürt içeren atıklara kireçli materyal ve organik madde uygulamasıyla pH artışı sağlanırken, EC değerlerinde ciddi düşüşler sağlanmaktadır (Clemente ve ark. 2003).

DTPA ile ekstrakte edilebilir $\mathrm{Fe}, \mathrm{Zn}, \mathrm{Mn}, \mathrm{Cu}, \mathrm{Ni}, \mathrm{Cr}, \mathrm{Pb}$ ve $\mathrm{Cd}$ konsantrasyonları sadece kireçli toprak uygulaması ile azalırken, bu değerler ortama ahır gübresi ilavesi ile artışa geçmiştir. $\mathrm{Pb}$ ve $\mathrm{Cd}$ konsantrasyonları üzerine kireçli toprak uygulamaları ile ahır gübresi ilavelerinin değişime bir etkisi olmamıştır. Orman ve Kaplan (2007) düşük pH, yüksek EC ve ağır metal içeriğine sahip kükürt madeni atıklarını kullanarak uyguladığı sera denemesinde kireçli toprak ve ahır gübresinin iyileştirici etkisini incelemişlerdir. Deneme sonuçlarına göre artan kireçli toprak uygulaması ortamdaki DTPA ile ekstrakte edilebilir ağır metal konsantrasyonunun azalmasına yol açtığı bildirmişlerdir.

Çizelge 3. Flotasyon atığına değişen düzeyde kireçli toprak ve ahır gübresi uygulamalarının ortam üzerindeki etkileri ${ }^{1}$.

Table 3. The effects of flotation waste amended with calcareous soil and farmyard manure on growing media.

\begin{tabular}{|c|c|c|c|c|c|c|c|c|c|c|c|}
\hline \multirow{2}{*}{ Parametreler } & \multirow{2}{*}{ FA.KT $\mathbf{T}_{10}$} & \multirow{2}{*}{ FA. $\mathbf{K T}_{20}$} & \multirow{2}{*}{ FA.KT $_{30}$} & \multirow{2}{*}{ FA.KT $_{40}$} & \multicolumn{2}{|c|}{ FA.KT $_{10}$} & \multicolumn{2}{|c|}{ FA.KT $_{20}$} & \multicolumn{2}{|c|}{ FA.KT $_{\mathbf{3 0}}$} & \multirow{2}{*}{ Önemlilik ${ }^{3}$} \\
\hline & & & & & $\mathbf{A G}_{4}$ & $\mathbf{A G}_{8}$ & $\mathbf{A G}_{4}$ & $\mathbf{A G}_{8}$ & $\mathbf{A G}_{4}$ & $\mathbf{A G}_{8}$ & \\
\hline $\mathrm{pH}$ & $3.511^{1}$ & $5.10 \mathrm{e}$ & $6.24 b$ & $6.58 \mathrm{a}$ & 3.541 & $3.64 \mathrm{~h}$ & $4.51 \mathrm{f}$ & $4.36 \mathrm{~g}$ & $5.78 \mathrm{~d}$ & $6.06 \mathrm{c}$ & $* * *$ \\
\hline $\mathrm{EC}\left(\mathrm{dS} \mathrm{m}^{-1}\right)$ & $2.71 \mathrm{~d}$ & $2.50 \mathrm{e}$ & $2.43 \mathrm{f}$ & $2.52 \mathrm{e}$ & $3.03 \mathrm{c}$ & $2.32 \mathrm{~g}$ & $2.70 \mathrm{~d}$ & $3.20 \mathrm{a}$ & $2.70 \mathrm{~d}$ & $3.15 \mathrm{~b}$ & $* * *$ \\
\hline $\mathrm{Fe}\left(\mathrm{mg} \mathrm{kg}^{-1}\right)$ & $286.20 \mathrm{c}$ & $224.97 \mathrm{f}$ & $156.35 \mathrm{~g}$ & $105.80 \mathrm{~h}$ & $334.45 \mathrm{~b}$ & $332.68 \mathrm{~b}$ & $333.88 \mathrm{~b}$ & $375.88 \mathrm{a}$ & $257.35 \mathrm{~d}$ & $234.03 \mathrm{e}$ & $* * *$ \\
\hline $\mathrm{Zn}\left(\mathrm{mg} \mathrm{kg}^{-1}\right)$ & $0.949 \mathrm{e}$ & $0.464 \mathrm{~g}$ & $0.671 \mathrm{fg}$ & $0.577 \mathrm{fg}$ & $1.283 \mathrm{~d}$ & $2.078 \mathrm{~b}$ & 0.762 ef & $1.618 \mathrm{c}$ & $1.331 \mathrm{~d}$ & $2.790 \mathrm{a}$ & $* * *$ \\
\hline $\operatorname{Mn}\left(\mathrm{mg} \mathrm{kg}^{-1}\right)$ & $25.930 \mathrm{~b}$ & $26.032 \mathrm{~b}$ & $15.090 \mathrm{~d}$ & $9.652 \mathrm{e}$ & $19.580 \mathrm{c}$ & $26.720 \mathrm{~b}$ & $27.770 \mathrm{~b}$ & $40.148 \mathrm{a}$ & $20.110 \mathrm{c}$ & $27.238 \mathrm{~b}$ & $* * *$ \\
\hline $\mathrm{Cu}\left(\mathrm{mg} \mathrm{kg}^{-1}\right)$ & $0.935 \mathrm{e}$ & $1.518 \mathrm{~d}$ & $1.895 \mathrm{~b}$ & $1.695 \mathrm{c}$ & $0.822 \mathrm{f}$ & $0.811 \mathrm{f}$ & $1.553 \mathrm{~d}$ & $1.495 \mathrm{~d}$ & $2.475 \mathrm{a}$ & $2.438 \mathrm{a}$ & $* * *$ \\
\hline $\mathrm{Co}\left(\mathrm{mg} \mathrm{kg}^{-1}\right)$ & $1.168 \mathrm{a}$ & $0.390 \mathrm{~d}$ & $0.370 \mathrm{~d}$ & $0.340 \mathrm{~d}$ & $0.685 \mathrm{c}$ & $1.125 \mathrm{a}$ & $0.375 \mathrm{~d}$ & $0.785 \mathrm{~b}$ & $0.243 \mathrm{e}$ & $0.343 \mathrm{~d}$ & $* * *$ \\
\hline $\mathrm{Ni}\left(\mathrm{mg} \mathrm{kg}^{-1}\right)$ & $7.018 \mathrm{~b}$ & $6.048 \mathrm{c}$ & $4.250 \mathrm{~d}$ & $3.010 \mathrm{e}$ & $8.883 \mathrm{a}$ & $9.368 \mathrm{a}$ & $4.758 \mathrm{~d}$ & $6.770 \mathrm{bc}$ & $4.965 \mathrm{~d}$ & $6.103 \mathrm{c}$ & $* * *$ \\
\hline $\mathrm{Cr}\left(\mathrm{mg} \mathrm{kg}^{-1}\right)$ & $0.017 \mathrm{~d}$ & $0.017 \mathrm{~d}$ & $0.016 \mathrm{~d}$ & $0.019 \mathrm{~d}$ & $0.054 \mathrm{~b}$ & $0.064 \mathrm{a}$ & $0.020 \mathrm{c}$ & $0.024 \mathrm{c}$ & $0.019 \mathrm{~d}$ & $0.019 \mathrm{~d}$ & $* * *$ \\
\hline $\mathrm{Pb}\left(\mathrm{mg} \mathrm{kg}^{-1}\right)$ & $0.040 \mathrm{e}$ & $0.062 \mathrm{~d}$ & $0.091 \mathrm{c}$ & $0.115 \mathrm{~b}$ & $0.040 \mathrm{e}$ & $0.037 \mathrm{e}$ & $0.061 \mathrm{~d}$ & $0.068 \mathrm{~d}$ & $0.102 \mathrm{bc}$ & $0.137 \mathrm{a}$ & $* * *$ \\
\hline $\mathrm{Cd}\left(\mathrm{mg} \mathrm{kg}^{-1}\right)$ & $0.022 \mathrm{e}$ & $0.037 \mathrm{~d}$ & $0.041 \mathrm{c}$ & $0.038 \mathrm{~d}$ & $0.023 \mathrm{e}$ & $0.025 \mathrm{e}$ & $0.033 \mathrm{~d}$ & $0.041 \mathrm{c}$ & $0.051 \mathrm{~b}$ & $0.062 \mathrm{a}$ & $* * *$ \\
\hline
\end{tabular}

${ }^{1}$ Değerler 4 tekerrür ortalamasıdır. ${ }^{2} \mathrm{Ayn}$ harf ile gösterilmeyen değerler arasındaki farklar $\% 5$ düzeyinde önemlidir. ${ }^{3 * * *}$ : \%0.1 düzeyinde önemlidir (P<0.001). 


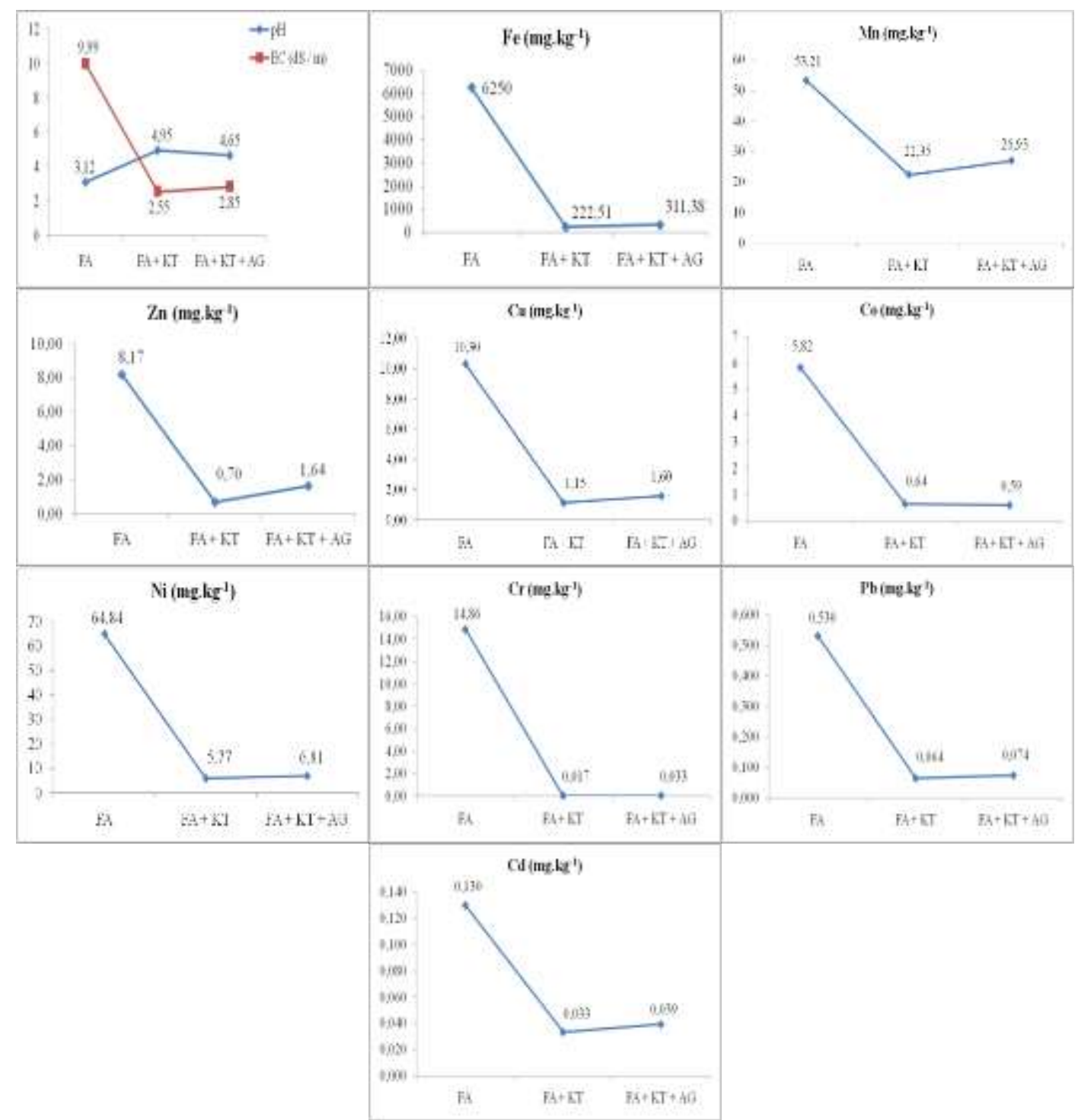

Şekil 1. Flotasyon atığına değişen düzeyde kireçli toprak ve ahır gübresi uygulamalarının ortam örneklerinin pH, EC, ağır metal (Alınabilir Fe, Zn, $\mathrm{Mn}, \mathrm{Cu}, \mathrm{Co}, \mathrm{Ni}, \mathrm{Cr}, \mathrm{Cd}$ ve $\mathrm{Pb}$ ) üzerindeki etkileri.

Figure 1. The values of average $\mathrm{pH}, \mathrm{EC}$ heavy metal (DTPA-extract $\mathrm{Fe}, \mathrm{Zn}, \mathrm{Mn}, \mathrm{Cu}, \mathrm{Co}, \mathrm{Ni}, \mathrm{Cr}, \mathrm{Cd}$ and $\mathrm{Pb}$ ) concentrations due to treatments of calcareous soil and calcareous soil with farmyard manure in growing media.

Çizelge 4. Flotasyon atığına değişen düzeyde kireçli toprak ve ahır gübresi uygulamalarının yetiştirilen çim bitkisi üzerindeki etkileri¹. Table 4. The effects of flotation waste amended with calcareous soil and farmyard manure on grass plant.

\begin{tabular}{|c|c|c|c|c|c|c|c|c|c|c|c|}
\hline \multirow{2}{*}{ Parametreler } & \multirow{2}{*}{ FA.KT $_{10}$} & \multirow{2}{*}{$\mathbf{F A . K T}_{20}$} & \multirow{2}{*}{ FA.KT $_{30}$} & \multirow{2}{*}{ FA.KT $_{40}$} & \multicolumn{2}{|c|}{ FA.KT $_{10}$} & \multicolumn{2}{|c|}{ FA.KT $_{20}$} & \multicolumn{2}{|c|}{ FA.KT $_{\mathbf{3 0}}$} & \multirow[t]{2}{*}{ Önemlilik $^{3}$} \\
\hline & & & & & $\mathbf{A G _ { 4 }}$ & $\mathbf{A G}_{8}$ & $\mathbf{A G}_{4}$ & $\mathbf{A G}_{8}$ & $\mathbf{A G}_{4}$ & $\mathbf{A G}_{8}$ & \\
\hline $\begin{array}{c}\text { Kuru Madde } \\
\text { Verimi }\left(\text { gr saksl }^{-1}\right)\end{array}$ & $32.808 \mathrm{~h}^{2}$ & $35.325 \mathrm{~g}$ & $35.960 \mathrm{f}$ & $36.328 \mathrm{f}$ & $34.850 \mathrm{~g}$ & $41.830 \mathrm{e}$ & $46.640 \mathrm{~d}$ & $48.710 \mathrm{~b}$ & $47.425 \mathrm{c}$ & $49.895 \mathrm{a}$ & $* * *$ \\
\hline $\mathrm{Fe}\left(\mathrm{mg} \mathrm{kg}^{-1}\right)$ & $248.85 \mathrm{~d}$ & $244.88 \mathrm{e}$ & $257.57 \mathrm{c}$ & $225.48 \mathrm{f}$ & $246.78 \mathrm{de}$ & $223.63 \mathrm{f}$ & $267.23 \mathrm{~b}$ & $275.45 \mathrm{a}$ & $264.77 \mathrm{~b}$ & $265.05 \mathrm{~b}$ & $* * *$ \\
\hline $\mathrm{Zn}\left(\mathrm{mg} \mathrm{kg}^{-1}\right)$ & $67.190 \mathrm{bc}$ & $64.722 \mathrm{~cd}$ & $54.487 \mathrm{~h}$ & $55.477 \mathrm{gh}$ & $72.047 \mathrm{a}$ & $72.488 \mathrm{a}$ & 59.663 ef & $69.093 \mathrm{ab}$ & $58.115 \mathrm{fg}$ & $62.248 \mathrm{de}$ & $* * *$ \\
\hline $\operatorname{Mn}\left(\mathrm{mg} \mathrm{kg}^{-1}\right)$ & $250.56 \mathrm{c}$ & $182.89 \mathrm{~d}$ & $170.18 \mathrm{f}$ & $175.18 \mathrm{e}$ & $287.50 \mathrm{~b}$ & $292.48 \mathrm{a}$ & $157.01 \mathrm{~g}$ & 142.041 & $147.03 \mathrm{~h}$ & $119.52 \mathrm{j}$ & $*$ \\
\hline $\mathrm{Cu}\left(\mathrm{mg} \mathrm{kg}^{-1}\right)$ & $0.438 \mathrm{~g}$ & $0.698 \mathrm{f}$ & $0.757 \mathrm{e}$ & $0.869 \mathrm{~d}$ & $0.647 \mathrm{f}$ & $0.889 \mathrm{~d}$ & $0.973 \mathrm{c}$ & $1.430 \mathrm{a}$ & $1.255 \mathrm{~b}$ & $1.295 \mathrm{~b}$ & $* * *$ \\
\hline $\mathrm{Co}\left(\mathrm{mg} \mathrm{kg}^{-1}\right)$ & $1.085 \mathrm{c}$ & $0.132 \mathrm{e}$ & $0.133 \mathrm{~d}$ & $0.130 \mathrm{e}$ & $3.700 \mathrm{a}$ & $3.563 \mathrm{~b}$ & $<$ b.s. e & $<$ b.s. e & $<$ b.s. e & $<$ b.s. e & $* * *$ \\
\hline $\mathrm{Ni}\left(\mathrm{mg} \mathrm{kg}^{-1}\right)$ & $24.385 \mathrm{c}$ & $15.725 \mathrm{~d}$ & $11.958 \mathrm{e}$ & $12.103 \mathrm{e}$ & $44.767 \mathrm{a}$ & $42.700 \mathrm{~b}$ & $11.918 \mathrm{e}$ & $12.075 \mathrm{e}$ & $11.025 \mathrm{e}$ & $10.788 \mathrm{e}$ & $* * *$ \\
\hline $\mathrm{Cr}\left(\mathrm{mg} \mathrm{kg}^{-1}\right)$ & $3.208 \mathrm{e}$ & $4.120 \mathrm{a}$ & $3.463 \mathrm{c}$ & $3.775 \mathrm{~b}$ & $2.345 \mathrm{~h}$ & $2.458 \mathrm{~g}$ & $3.350 \mathrm{~d}$ & $2.643 \mathrm{f}$ & $3.225 \mathrm{e}$ & $2.465 \mathrm{~g}$ & $* * *$ \\
\hline $\mathrm{Pb}\left(\mathrm{mg} \mathrm{kg}^{-1}\right)$ & $1.858 \mathrm{c}$ & $1.358 \mathrm{e}$ & $1.733 \mathrm{~cd}$ & $2.095 \mathrm{~b}$ & $2.480 \mathrm{a}$ & $2.490 \mathrm{a}$ & $2.553 \mathrm{a}$ & $1.753 \mathrm{~cd}$ & $1.625 \mathrm{~d}$ & $2.440 \mathrm{a}$ & $* * *$ \\
\hline $\mathrm{Cd}\left(\mathrm{mg} \mathrm{kg}^{-1}\right)$ & $0.333 \mathrm{f}$ & $0.493 \mathrm{~b}$ & $0.505 \mathrm{~b}$ & $0.565 \mathrm{a}$ & $0.290 \mathrm{~g}$ & $0.328 \mathrm{fg}$ & $0.420 \mathrm{de}$ & $0.405 \mathrm{e}$ & $0.455 \mathrm{~cd}$ & $0.473 \mathrm{bc}$ & $* * *$ \\
\hline
\end{tabular}

${ }^{1}$ Değerler 4 tekerrür ortalamasıdır. ${ }^{2}$ Aynı harf ile gösterilmeyen değerler arasındaki farklar \% 5 düzeyinde önemlidir. ${ }^{3} * * *: \%$ 0.1 düzeyinde önemlidir $(\mathrm{P}<0.001)$. 


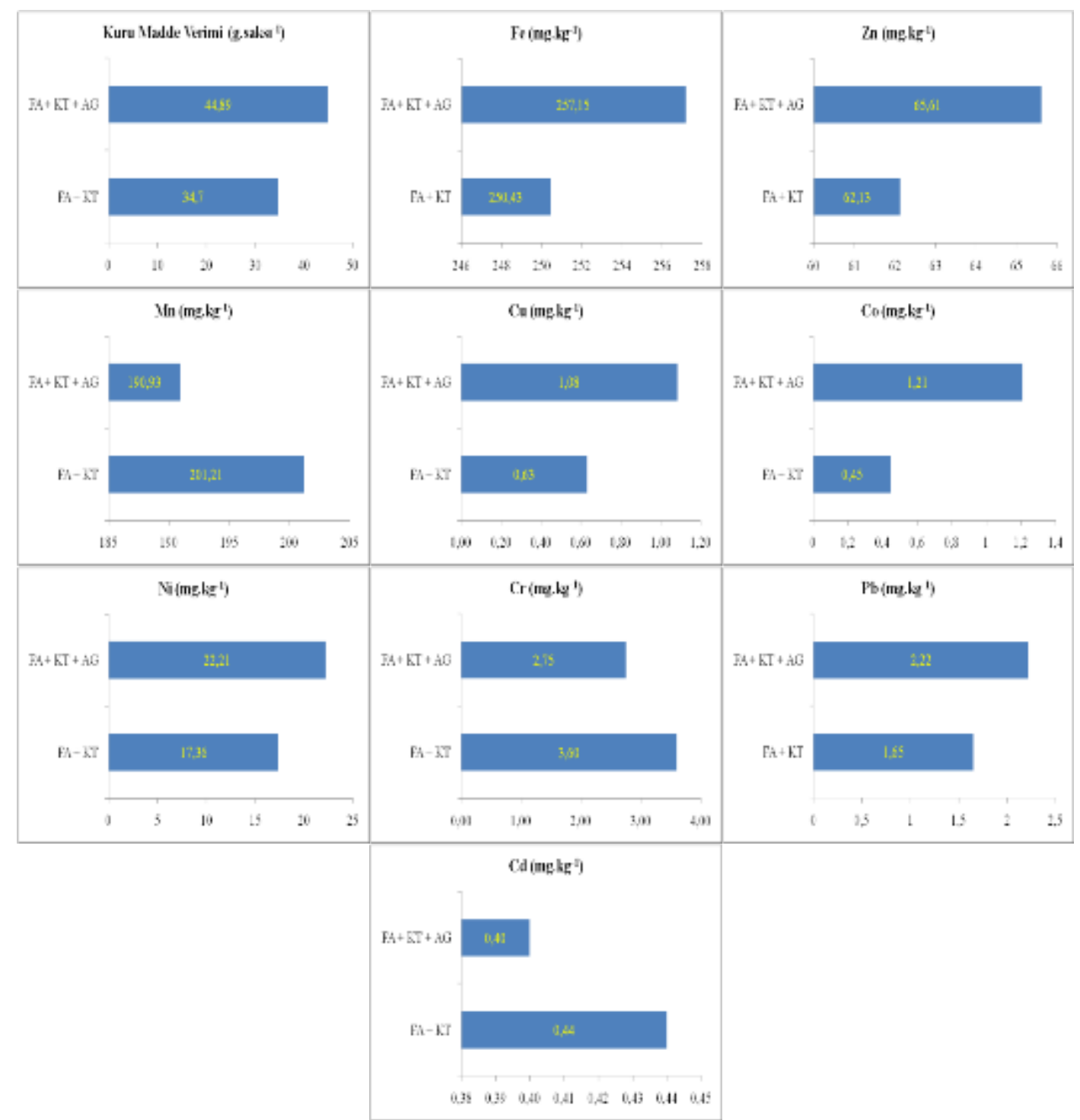

Şekil 2. Flotasyon atığına değişen düzeyde kireçli toprak ve ahır gübresi uygulamalarının bitki örneklerinin kuru madde verimi ve ağır metal (Alınabilir $\mathrm{Fe}, \mathrm{Zn}, \mathrm{Mn}, \mathrm{Cu}, \mathrm{Co}, \mathrm{Ni}, \mathrm{Cr}$, Cd ve $\mathrm{Pb}$ ) üzerindeki etkileri.

Figure 2. The values of average heavy metal ( $\mathrm{Fe}, \mathrm{Zn}, \mathrm{Mn}, \mathrm{Cu}, \mathrm{Co}, \mathrm{Ni}, \mathrm{Cr}, \mathrm{Cd}$ and $\mathrm{Pb}$ ) concentrations and dry weight of shoot due to treatments of calcareous soil and calcareous soil with farmyard manure in growing media.

Yapılan kireçli toprak ve ahır gübresi uygulamas1 sonrasında en yüksek kuru madde verimi değeri ahır gübresinin en üst oranı olan \%8'lik karışımda göstermiştir. Maden atıklarının besin içeriğinin zenginleştirmesi ve fiziksel özelliklerin iyileştirilmesi amacıyla ahır gübresi kullanımı çok etkili olmaktadır (Bradshaw ve Chadwick 1980).

Sadece kireçli toprak uygulaması olan çim bitkilerinin Mn, $\mathrm{Cr}$ ve $\mathrm{Cd}$ konsantrasyonları artış gösterirken, ahır gübresi ilavesi olan uygulamalarda kuru madde verimi, $\mathrm{Fe}, \mathrm{Zn}, \mathrm{Cu}, \mathrm{Co}, \mathrm{Ni}$ ve $\mathrm{Pb}$ konsantrasyonları artış göstermişlerdir. Yetiştirme ortamlarına kireçli toprak ilavesi ile aşırı asidik olan ortam pH'sını daha makul seviyelere çekmiş olması, ayrıca ahır gübresi ilavesi ile de ortamdaki besin elementi $(\mathrm{N}, \mathrm{P}$ ve $\mathrm{K})$ ihtiyacını karşılaması çim bitkisinin gelişimini de olumlu yönde etkilemiştir (Chiu ve ark. 2006; Yılmaz ve Alagöz 2010).

\section{Sonuç}

Keçiborlu Kükürt İşletmesi atık havuzları, kükürt cevherinin işlenmesi sırasında flotasyon aşamasında meydana gelen atıkları içerir ve işletmenin faaliyette olduğu dönem boyunca biriken üretim atığının 1 milyon tona vardığ $\breve{g}_{1}$ tahmin edilmektedir. Bölgedeki bu atığın çevredeki diğer tarım topraklarını, yeraltı su kaynaklarını ve yöre halkının sağlığını ciddi boyutlarda tehdit ettiği düşünülmektedir. $\mathrm{Bu}$ olumsuzlukların giderilmesi için atıkların en kısa sürede 1slah edilmesi gerekliliği ortaya çıkmaktadır. Yapılan çalışmada flotasyon atığına sadece kireçli toprak uygulamasıyla DTPA ile ekstrakte edilebilir ağır metal konsantrasyonu ortam pH'sının yükselmesi ile düşmüştür. Fakat ahır gübresi ilavesi olan uygulamalarda artan $\mathrm{pH}$ ile birlikte hem ağır metal konsantrasyonu hem de çim bitkisinin 
gelişiminde bir artış gözlemlenmiştir. Buradaki ağır metal konsantrasyonundaki artışın ortama uygulanan ahır gübresinin şelatlayıc1 etkisinden kaynaklandığ 1 düşünülmektedir. Keçiborlu Kükürt Fabrikası flotasyon atığı doğru bir şekilde idare edilmezse çevresel kirlenme için çok büyük bir faktör durumundadır. Su erozyonuna karşı dayanıklılık ve toz kontrolü için kimyasal ve fiziksel teknikler vardır. Ancak atık alanların çeşitli iyileştirici materyallerle ıslah edilmesinin yanı sıra bitki örtüsünün kullanımı ile daha gerçekçi ve uzun süreli bir başarı elde edilebilir. Bu hedeflenen amaçlara ulaşmada yöntem olarak fitoremediasyonun faydalı olacağı yapılan bu çalışma ile ortaya konulmuştur.

\section{Teşekkür}

$\mathrm{Bu}$ çalışma Akdeniz Üniversitesi Bilimsel Araştırma Projeleri Birimi'nin 2008.02.0121.022 numaralı Yüksek Lisans Tez projesi kapsamında desteklenmiştir.

\section{Kaynaklar}

Açıkgöz E (1994) Çim alanlar, yapım ve bakım tekniği. Çevre peyzaj mimarlığ 1 yay. No: 4, Bursa, s. 203.

Anonim (1988) Meyve, sebze ve mamulleri nitrit ve nitrat tayini moleküler absorpsiyon spektrofotometrik metot. Türk Standard1, ICS 67.080, TS 6183/Aralık.

Bradshaw AD, Chadwick MJ (1980) The restoration of land. Blackwell scientific, Oxford. 1-352.

Chiu KK, Ye ZH, Wong MH (2006) Growth of vetiveria zizanioides and phragmities australis on $\mathrm{Pb} / \mathrm{Zn}$ and $\mathrm{Cu}$ mine tailings amended with manure compost and sewage sludge: A greenhouse study. Bioresource Technology 97: 158-170.

Clemente R, Walker DJ, Roig A, Bernal MP (2003) Heavy metal bioavailability in a soil affected by mineral sulphides contamination following the mine spillage at aznacollar (Spain). Biodegradation 14: 199-205.

Cunningham SD, Berti WR (1995) Remediation of contaminated soils with green plants: an overview. in Vitro Cell Dev. Biol: 29: 207219.

Cunningham SD, Ow DW (1996) Promises and prospects of phytoremediation. Plant physiology 110: 715-719.

Epa (US Environmental Protection Agency) (2000) Introduction to phytoremediation EPA/600/r-99/107, Cincinati, Ohio, U.S.A., pp. 72 .

Freed R, Einensmith SP, Guetz S, Reicosky D, Smail VW, Wolberg P (1989) User's guide to Mstat-C, A Analysis of agronomic research experiments. Michigan State University, U. S. A.
Gülcü S, Bayram A, Celik S (2007) Isparta-Keçiborlu kükürt maden ocağında yapılan ağaçlandırmaların değerlendirilmesi. https://yayin.ogm.gov.tr/yaydepo/1603.pdf, Erişim 22 Nisan 2019.

Jackson MC (1967) Soil chemical analysis. Prentice hall of India Private Limited, New Delhi, USA.

Johnson MS, Cooke JA, Stevenson JKW (1994) Revegetation of metalliferous wastes and land after metal mining. in: Hester, RE, Harrison RM (Eds.), Mining and its environmental impact. Issues in environmental science and technology 1. Royal society of chemistry London, pp. 31-48.

Kacar B, İnal A (2008) Bitki analizleri. Nobel Yayın Dağıtım Ltd. Şti. Nobel Yayın No: 1241. 63, ISBN 978-605-395-036-3, 1. Basim, Ankara, s. 894

Kocaer FO, Başkaya HS (2003) Metallerle kirlenmiş toprakların temizlenmesinde uygulanan teknolojiler. Uludağ ÜniversitesiMimarlık Fakültesi Dergisi. Cilt 8, sayı 1.

Lindsay WL, Norvell WA (1978) Development of a DTPA Soil Test for Zinc, Iron, Manganese and Copper. Soil Sci. Amer. Jour. 42(3): 421-428.

Orman Ş, Kaplan M (2007) Effects of calcareous soil and farmyard manure on revegetation of sulphur mine tailings. Fresenius environment bulletin, Vol: 16; No: 10.

Raskin I, Salt ED, Blaylock M, Kumar PBAN, Dushenkov V, Ensley DB, Chet I (1994) Phytoremediation: A Novel strategy for the removal of toxic metals from the environment using plants. Bio/Technology 13, pp. 468-474.

Sarı M, Aksoy T, Köseoğlu T, Kaplan M, Kılıç Ş, Pilanalı N (1993) Akdeniz üniversitesi yerleşim alanının detaylı toprak etüdü ve ideal arazi kullanım planlaması. Akdeniz Üniv. Yayınları, Antalya, s. 59.

Simón M, Ortiz I, García I, Fernández J, Dorronsoro C, Aguilar J (1999) Pollution of soils by the toxic spill of a pyrite mine (Aznalcóllar, Spain). Sci Total Environ 242: 105-115.

Sposito G, Lund LJ, Chang AC (1982) Trace metal in Arid zone field soils amended with sewage sludge: I. Fractionation of $\mathrm{Ni}, \mathrm{Cu}, \mathrm{Zn}$, $\mathrm{Cd}$ and $\mathrm{Pb}$ in solid phase. Soil. Sci. Soc. Am. J. 40, pp. 665-672.

Vanlı Ö, Yazgan M (2006) Ağır metallerle kirlenmiş toprakların temizlenmesinde Fitoremediasyon Tekniği http://www.tarimsal.com/fitoremediasyon/fitoremediasyon.htm.

Williamson A, Johnson MS (1981) Reclamation of metalliferous mine wastes. In: Lepp NW (Ed.). Effect of heavy metal pollution on plants. Vol. 2. Metals in the Environment. Applied Science Publishers Ltd., Barking, pp. 185-212.

Yılmaz E, Alagöz Z (2010) Effects of short-term amendments of farmyard manure on some soil properties in the Mediterranean Region-Turkey, Journal of Food Agriculture \& Environment 8: 859- 862 . 